\title{
Cardiac Rehabilitation for Aboriginal and Torres Strait Islander people in Western Australia
}

\author{
Sandra Hamilton ${ }^{1 *}$ (D) Belynda Mills ${ }^{1}$, Shelley McRae ${ }^{2}$ and Sandra Thompson ${ }^{1}$
}

\begin{abstract}
Background: Cardiovascular disease (CVD) is a leading cause of morbidity and mortality in Australia. Australian Aboriginal and Torres Strait Islander (Indigenous) people have higher levels of CVD compared with non-Indigenous people. Cardiac Rehabilitation (CR) is an evidence-based intervention that can assist with reducing subsequent cardiovascular events and rehospitalisation. Unfortunately, attendance rates at traditional CR programs, both globally and in Australia, are estimated to be as low as 10-30\% and Indigenous people are known to be particularly under-represented. An in-depth assessment was undertaken to investigate the provision of $C R$ and secondary preveniton services in Western Australia (WA) with a focus on rural, remote and Indigenous populations. This paper reports on the findings for Indigenous people.

Methods: Cardiac rehabilitation and Aboriginal Medical Services $(n=38)$ were identified for interview through the Heart Foundation Directory of Western Australian Cardiac Rehabilitation and Secondary Prevention Services 2012. Semi-structured interviews with CR coordinators were conducted and included questions specific to Indigenous people.

Results: Interviews with coordinators from 34 CR services (10 rural, 12 remote, 12 metropolitan) were conducted. Identification of Indigenous status was reported by $65 \%$ of coordinators; referral and attendance rates of Indigenous patients differed greatly across WA. Efforts to meet the cultural needs of Indigenous patients varied and included case management (32\%), specific educational materials (35\%), use of a buddy or mentoring system (27\%), and access to an Aboriginal Health Worker (71 \%). Staff cultural awareness training was available for $97 \%$ and CR guidelines were utilised by $77 \%$ of services.
\end{abstract}

Conclusion: The under-representation of Indigenous Australians participating in CR, as reported in the literature and more specifically in this study, mandates a concerted effort to improve services to better meet the needs of Indigenous patients with CVD as part of closing the gap in life expectancy. Improving access to culturally appropriate CR and secondary prevention in WA must be an important component of this effort given the high rates of premature cardiovascular disease affecting Indigenous people. Our findings also highlight the importance of good systematic data collection across services. Health pathways that ensure continuity of care and alternative methods of CR delivery with dedicated resources are needed.

Keywords: Indigenous, Cardiac Rehabilitation, Secondary Prevention, Western Australia, Access, Health Pathways, Alternative Methods

\footnotetext{
* Correspondence: sandy.hamilton@uwa.edu.au

${ }^{1}$ Western Australian Centre for Rural Health, University of Western Australia,

35 Stirling Highway, Crawley, WA 6009, Australia

Full list of author information is available at the end of the article
} 


\section{Background}

Cardiovascular disease (CVD) is a leading cause of morbidity and mortality and the leading disease category for health-care expenditure in Australia [1, 2]. Cardiovascular disease accounted for $31 \%$ of all deaths in 2011 with coronary heart disease (CHD) accounting for $15 \%$ of all deaths and $47 \%$ of CVD deaths, many of which are premature and preventable [3]. Australian Aboriginal and Torres Strait Islander (Indigenous) people have higher levels of CVD compared with non-Indigenous people. In 2011-13, Indigenous Australians were 1.6 times more likely to report CVD and their rate of acute coronary events was 2.5 times higher than non-Indigenous Australians [4, 5]. Cardiovascular disease also occurs at a younger age in Indigenous Australians, some 10 years earlier than in non-Indigenous people, with rates in 3554 year age group four times greater than nonIndigenous Australians [6]. These discrepancies in rates are profound and have been reported for Indigenous Western Australians for myocardial infarction,[7] atrial fibrillation,[8] and heart failure [9].

Cardiac Rehabilitation (CR) and secondary prevention is well-recognised as effective management for cardiac patients and results in improved clinical and behavioural outcomes including reductions in subsequent cardiovascular events and hospitalizations and improved survival [10-12]. However, more than $40 \%$ of CHD events, $50 \%$ of CHD death and $35 \%$ of nonfatal myocardial infarctions occur in people with existing CHD [13]. Unfortunately participation rates at traditional $\mathrm{CR}$ programs, both globally and in Australia, are estimated to be as low as $10-30 \%$ with an under-representation of Indigenous people [10, 14-18]. Vulnerable patient populations such as Indigenous patients, women, older patients, socioeconomic disadvantaged, minority ethnic populations, rural patients and those with more prevalent comorbidities are less likely to adhere and complete CR [17, 19, 20]. Low participation rates represent healthcare service (health professional and provision/systems of care) failures and patient-related barriers to attendance, participation or adherence despite their being referred [15-31]. Failure to refer patients to CR is a major barrier to participation [32] with referral rates varying from $10-60 \%$ [25, 32-35]. Factors positively related to referral have been identified and include younger age, male, Caucasian, patients undergoing percutaneous intervention or coronary artery bypass grafting and a positive attitude to CR by the referring physician or health professional [25, 32-36]. Barriers to CR use for Indigenous Australians have been identified and include: extended family responsibilities [37, 38]; issues with family support and understanding [38]; sociocultural appropriateness of the program [37]; lack of knowledge about CR [37, 38]; low income [37]; connection between colonialism and health services [37]; disempowering health messages in the media [37]; and the younger age of the Indigenous patients [37].

Approximately, $13 \%$ of all Indigenous people live in Western Australia (WA), comprising approximately $3.1 \%$ of the total WA population [39]. Rural and remote regions of WA have a substantially higher Indigenous population, especially the Kimberley (40.0\%), Pilbara (12.0\%) and Midwest regions (10.0\%) [39]. In a 2008 study, Thompson et al. examined and described health professionals' awareness, implementation, and perspectives on the barriers to the implementation of the 2005 National Health and Research Council's (NHMRC) Strengthening Cardiac Rehabilitation and Secondary Prevention for Aboriginal and Torres Strait Islander peoples: A Guide for Health Professionals [40, 41]. The guide's key measures for successful $\mathrm{CR}$ in Indigenous Australians are summarised in Table 1 [40-42]. Twentyfour health professionals from 17 services in WA were interviewed; suboptimal awareness and limited uptake of the NHMRC guidelines was identified [40]. Inpatient and outpatient CR services were limited for Indigenous patients and use of Indigenous resources was low. Workforce issues, cultural competence and service linkages emerged as factors impacting on the design and delivery of CR services for Indigenous people in WA. It was concluded that that the disproportionate burden of CVD mortality and morbidity in Indigenous people required urgent attention, dedicated resources and alternative approaches to CR [40].

The recently released Australian Cardiovascular Health and Rehabilitation (ACRA) Core Components of

Table 1 Key measures for successful cardiac rehabilitation in Indigenous Australians [40-42]

1. Ensure cultural safety is integral to the core business of an organisation and supported at all levels within the organisation.

2. Involve an Aboriginal Health Worker or Liaison Officer and family members in the care of Indigenous Australians and develop flexible approaches in a setting that is comfortable to them, highlighting the importance of $C R$.

3. Draw on existing CR and secondary prevention services as appropriate and engage with the local community networks.

4. Ensure community involvement and control in planning, implementing and evaluating programs, including the development of culturally appropriate educational resources.

5. Develop and sustain partnerships between organisations, including a referral network.

6. Take the specific needs of Indigenous Australians into consideration in planning and delivering CR and secondary prevention and develop supportive protocols, policies and procedures that address these needs.

7. Develop specialist educational resources and training for continuing professional development and support of all health professionals in heart care, including Aboriginal Health Workers, Liaison Officers and Allied Health Assistants. 
Cardiovascular Disease Secondary Prevention and Cardiac Rehabilitation 2014 [43] and the Department of Health, Western Australia Cardiovascular Rehabilitation and Secondary Prevention Pathway Principles for Western Australia [44] acknowledge the disparities in the management and secondary prevention of CVD for Indigenous Australians.

This in-depth assessment investigated the provision of $\mathrm{CR}$ and secondary prevention services in WA with a focus on rural, remote and Indigenous populations. This paper reports on the findings for Indigenous services, in particular service provision, culturally appropriate approaches for Indigenous patients including availability of Indigenous staff, staff cultural awareness training, and $\mathrm{CR}$ guideline use.

\section{Methods}

\section{Study design}

A mixed methods study utilising structured interviews of CR Coordinators was undertaken. Quantitative and qualitative interview questions were based on the $\mathrm{Na}$ tional Heart Foundation of Australia and the Australian Cardiac Rehabilitation Association Recommended Framework for Cardiac Rehabilitation 04 [14]. Table 2 documents the topics covered in the questionnaire. The semi-structured interview guide was developed, tested and modified prior to use and included questions specific to Indigenous people by exploring the use of culturally appropriate approaches for Indigenous patients, demographic data, staff cultural awareness training, and the availability of Indigenous staff (Table 3). Quantitative data collection was based on CR coordinator reports at interview and the interviewer recorded this on the interview guide (Table 2). CR coordinators were asked to send a summary of data through via email if possible. Quantitative data was entered and analysed in SPSS.

Cardiac rehabilitation services, Aboriginal Medical Services and program coordinators were identified through the Heart Foundation (HF) Directory of Western Australian Cardiac Rehabilitation and Secondary Prevention Services 2012. Services identified through this sampling frame were contacted and coordinators given an explanation of the study and invited to participate. A Participant Information Sheet was emailed and a $60 \mathrm{~min}$ interview scheduled at the coordinator's convenience. Coordinators returned a signed consent form and were re-consented verbally at the beginning of the interview for their responses to be digitally recorded. The Western Australian Country Health Service and University of Western Australia Human Ethics Committees approved the study.

\section{Data analysis}

Quantitative data was analysed using IBM SPSS Statistics 22 and descriptive statistics utilised to report both continuous and categorical data. Data was exported to Excel and qualitative data relating to Indigenous people analysed manually by the principal investigator.

\section{Results}

Services and geographical locations

Of the 70 services listed in the Heart Foundation Cardiac Rehabilitation Directory 2012, 38 were identified for interview as 12 programs were discontinued, 14 of 18 Aboriginal Medical Services (AMSs) reported not providing $\mathrm{CR}$, and 6 services listed (including two AMSs) were not able to be contacted (Fig. 1). Two AMSs (one metropolitan and one rural) offered a specific chronic condition management program for their patients that included a strong focus on heart health. Thirty four programs $(90 \%$ of those identified for interview) were interviewed from March to July 2015; four declined due to a lack of capacity.

Of the programs identified for interview, 26 programs (68\%) were located in the four health regions in south west WA: the Wheatbelt, South West, Great Southern,

Table 2 Semi-structured interview questionnaire

\begin{tabular}{|c|c|}
\hline Component & Content \\
\hline Core component of CR & $\begin{array}{l}\text { Inpatient CR: Type of program; type of facility; main elements of inpatient CR (basic information and } \\
\text { reassurance, supportive counselling, mobilization and resumption of activities, discharge planning, and referral } \\
\text { to outpatient CR and ongoing care). } \\
\text { Outpatient CR: Pre-cardiovascular surgery review; assessment, review and follow-up; low or moderate intensity } \\
\text { physical activity; education, discussion and counselling; ongoing assessment and management, and monitoring } \\
\text { and evaluation. }\end{array}$ \\
\hline Program information & $\begin{array}{l}\text { Type of health service; type of program delivery; patient eligibility; program duration and frequency; } \\
\text { attendance fee; patients from diverse populations; and patient monitoring and referral for further medical } \\
\text { review. }\end{array}$ \\
\hline Referral and attendance & $\begin{array}{l}\text { Patient referral pathway; patient attendance and completion numbers; demographic data; patient outcomes; } \\
\text { and exit strategies for patients on completion. }\end{array}$ \\
\hline $\begin{array}{l}\text { Program coordination and } \\
\text { multidisciplinary team }\end{array}$ & $\begin{array}{l}\text { Dedicated program coordinator; multidisciplinary team availability; use of CR guidelines; sustainability of } \\
\text { program and program and service contact details. }\end{array}$ \\
\hline
\end{tabular}

Key: CR Cardiac Rehabilitation 
Table 3 Questions relating to Indigenous Patients

\begin{tabular}{|c|c|}
\hline & Question \\
\hline \multirow{2}{*}{$\begin{array}{l}\text { Culturally appropriate programs or } \\
\text { approaches }\end{array}$} & Describe any programs or approaches that are used to meet the needs of diverse population groups? \\
\hline & $\begin{array}{l}\text { Describe if and how your program: } \\
\text { a. Uses case management for Aboriginal and Torres Strait Islander or other culturally diverse patients that } \\
\text { covers the process of care from tests and/or procedures through to CR? } \\
\text { b. Uses education materials on common cardiovascular conditions, tests, interventions, medications and CR } \\
\text { designed for Aboriginal and Torres Strait Islander people? } \\
\text { c. Employs or has access to an Aboriginal Health Worker to assist you and your Aboriginal and Torres Strait } \\
\text { Islander or other culturally diverse patients? } \\
\text { d. Operates a buddy and/or mentoring systems for patients whose family or carer is not available to take part } \\
\text { in the decision-making process or accompany them to hospital? }\end{array}$ \\
\hline Demographic data & $\begin{array}{l}\text { What are the demographics of the patients who attend your program? } \\
\% \text { Male } \\
\% \text { Female } \\
\% \text { Indigenous } \\
\text { Average age }\end{array}$ \\
\hline $\begin{array}{l}\text { CR guidelines } \\
\text { One of several guidelines listed }\end{array}$ & $\begin{array}{l}\text { Which CR guideline(s) guide your program? } \\
\text { National Health and Medical Research Council. Strengthening Cardiac Rehabilitation and Secondary Prevention } \\
\text { for Aboriginal and Torres Strait Islander Peoples: A Guide fro Health Professionals. }\end{array}$ \\
\hline Staff cultural awareness training & Explain any cultural awareness training that staff in your program undertake? \\
\hline $\begin{array}{l}\text { Availability of Indigenous staff } \\
\text { Both questions included Aboriginal } \\
\text { Health Worker }\end{array}$ & $\begin{array}{l}\text { Do you have a multidisciplinary team involved in your program? If yes, please indicate all relevant health } \\
\text { professionals that are available to your program and if possible indicate hours per week. } \\
\text { If your program does not have a multidisciplinary team, what health professionals does your program have } \\
\text { access to? }\end{array}$ \\
\hline
\end{tabular}

and Metropolitan Perth. The remaining $32 \%$ were spread across the Kimberley $(n=3)$, Pilbara $(n=3)$, Midwest $(n=4)$, and Goldfields $(n=2)$. The majority of services (68\%) were public hospital-based, $29 \%$ were community-based and one private service was both hospital and community-based. Rural and remote services were mostly public hospital-based (93\%) compared with $42 \%$ of metropolitan services. Metropolitan services were more likely to provide comprehensive CR programs (58 \%) compared with rural $(30 \%)$ and remote services (17\%). Three regional programs offered dedicated $\mathrm{CR}$ exercise programs with ad hoc education and smaller rural and remote sites offered generic chronic condition exercise programs which cardiac patients could attend for CR. One remote Nursing Post offered telephone education and support.

Dedicated program coordinators were more likely to be physiotherapists $(67 \%)$ or registered nurses $(24 \%)$ (Table 4); two programs employed exercise physiologists and one program employed a health promotion officer. All rural and $83 \%$ of remote program coordinators were physiotherapists and the hours dedicated to the role of program coordinator indicated it was a part time role (Table 4), with the majority stating it was only one component of their overall role. Program coordinators were more likely to be female $(75 \%)$ than male and this was evenly distributed over rural, remote and metropolitan programs.

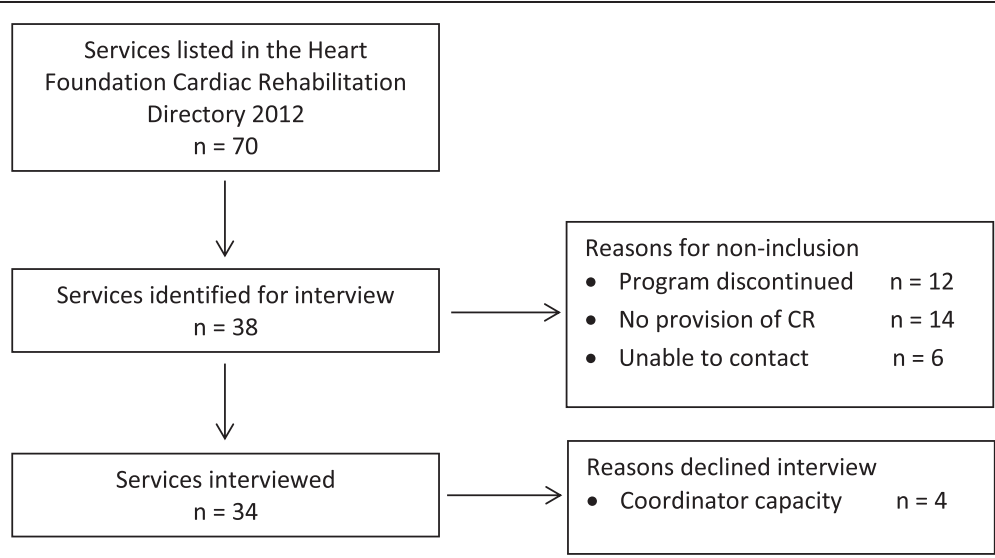

Fig. 1 Flow chart of cardiac rehabilitation service identification and interview 
Table 4 Demography of dedicated Cardiac Rehabilitation Coordinators

\begin{tabular}{|c|c|c|c|c|}
\hline & $\begin{array}{l}\text { Overall } \\
\%(n)\end{array}$ & $\begin{array}{l}\text { Rural } \\
\%(n)\end{array}$ & $\begin{array}{l}\text { Remote } \\
\%(n)\end{array}$ & $\begin{array}{l}\text { Metropolitan } \\
\%(n)\end{array}$ \\
\hline \multicolumn{5}{|c|}{ Health discipline of Coordinator } \\
\hline$\cdot \mathrm{RN}$ & $18(6)$ & & $17(2)$ & $34(4)$ \\
\hline - $\mathrm{RN}$ certified in CR & $3(1)$ & & & $8(1)$ \\
\hline - Nurse Practitioner & $3(1)$ & & & $8(1)$ \\
\hline - Physiotherapist & $67(23)$ & $100(10)$ & $83(10)$ & $25(3)$ \\
\hline - Exercise Physiologist & $6(2)$ & & & $17(2)$ \\
\hline - Health Promotion officer & $3(1)$ & & & $8(1)$ \\
\hline \multicolumn{5}{|c|}{ Full time equivalent in CR role } \\
\hline$\cdot \leq 0.8$ (range $0.2-0.8$ ) & $79(27)$ & $100(10)$ & $100(12)$ & $42(5)$ \\
\hline$\cdot 1.0$ & $21(7)$ & $0(0)$ & $0(0)$ & $58(7)$ \\
\hline Months in position & Months & Months & Months & Months \\
\hline - mean $\pm S D$ & $52.8 \pm 67.7$ & $65.1 \pm 97.2$ & $48.5 \pm 58.7$ & $47.8 \pm 53.4$ \\
\hline - Range (min-max) & $1.0-276$ & $3.0-276$ & $1.0-192$ & $3.0-192$ \\
\hline
\end{tabular}

Key: RN Registered nurse, $C R$ Cardiac rehabilitation

The length of time that the coordinators had worked in their role was widely variable and the range was wide in all program settings (Table 4).

\section{Identification of and services for Indigenous patients}

Overall, $65 \%$ of coordinators reported that there were processes for identification of Indigenous Australians in their service. A higher proportion of services $(75 \%)$ in remote areas reported identification of Indigenous people compared with $50 \%$ in rural and $67 \%$ in metropolitan settings (Table 5). Western Australia (and Australia) has no standard system of CR data collection so our quantitative analysis is limited, based on coordinator reports rather than analysis of consistent, routinely collected service data. All program coordinators reported receiving patient referrals from metropolitan public hospitals. Other referral sources included regional public hospitals (50\%), metropolitan (60\%) and regional private hospitals (35\%), general practice (60\%), Aboriginal Medical Services (50\%) and self-referrals (40\%). One coordinator received referrals from private cardiology rooms and two coordinators situated in a remote service received referrals from remote Aboriginal community clinics. Cardiac rehabilitation coordinators, nursing and allied health staff and cardiologists were most likely to make the referral and the most common method of referral was a referral letter or a copy of the discharge letter. Other methods of referral included telephone calls, facsimile, internal eReferral and email. The length of time from discharge to receipt of referral varied from on discharge (46\%), one to two weeks (15\%), two to four weeks (18\%), one to three months (12\%) and other $(9 \%)$.

Reported referral rates varied widely and were greater for metropolitan services than for rural and remote services. The majority of rural and remote services received less than 5 Indigenous and non-Indigenous cardiac referrals per month, some less than 5 per year. The percentage of patients attending CR programs who are Indigenous varied widely across the regions: $50-75 \%$ in the Kimberley, 5-25 \% in the Pilbara, and 0-10\% in other regional areas. Metropolitan services reported

Table 5 Identifying and meeting the needs of Indigenous Australians

\begin{tabular}{|c|c|c|c|c|}
\hline & $\begin{array}{l}\text { Overall } \\
\%(n)\end{array}$ & $\begin{array}{l}\text { Rural } \\
\%(n)\end{array}$ & $\begin{array}{l}\text { Remote } \\
\%(n)\end{array}$ & $\begin{array}{l}\text { Metropolitan } \\
\%(n)\end{array}$ \\
\hline Identification of Indigenous Australians - \% Yes & $65(34)$ & $50(10)$ & $75(12)$ & $67(12)$ \\
\hline Case Management for Indigenous Australians - \% Yes & $32(34)$ & $50(10)$ & $17(12)$ & $33(12)$ \\
\hline Specific Educational Materials for Indigenous Australians - \% Yes & $35(34)$ & $20(10)$ & $25(12)$ & $58(12)$ \\
\hline Access to AHW - \% Yes & $71(34)$ & $80(10)$ & $83(12)$ & $50(12)$ \\
\hline Buddy or Mentoring System for Indigenous Australians - \% Yes & $27(34)$ & $30(10)$ & $25(12)$ & $25(12)$ \\
\hline Cultural awareness CPD for staff - \% Yes & $97(33)$ & $100(10)$ & $100(12)$ & $91(11)$ \\
\hline CR guidelines $-\%$ Yes & 77 (33) & $60(10)$ & $67(12)$ & $100(11)$ \\
\hline
\end{tabular}


between zero and less than $5 \%$; many respondents suggesting that Indigenous patients were referred to the AMS. Both AMS-based programs reported that $100 \%$ of their participants were Indigenous. There was a disparity between genders attending $\mathrm{CR}$ as two thirds of patients (Indigenous and non-indigenous) who attended were male (63\% male vs $37 \%$ female overall, $60 \%$ vs $40 \%$ rural and metropolitan and $66 \%$ vs $33 \%$ at remote services). Attendance rates for Indigenous patients was collected but not by gender. Available data indicates a wide range of program completion of patients who commenced CR: a range of 30-100 \% overall with CR completion of $30-100 \%$ in rural, $10-90 \%$ in remote and 65 $90 \%$ in metropolitan services.

For the majority of programs ( $88 \%)$ there was no participation fee. Two remote programs charged minimum fees for either the Heart Moves program (gold coin donation) or the first class at a Recreation Centre (\$3.50). Two private metropolitan programs charged a fee with the amount of reimbursement of out-of-pocket expenses dependent on the private health insurance fund. Transport was the other cost for patients and related to private car use and parking or public transport use. Public transport was more accessible in metropolitan settings. Many programs had some measures in place to assist patients with transport: these included an AMS or voluntary bus service, taxi vouchers, Home and Community Care Program (HACC) services, and Aboriginal Liaison Officers providing transport.

\section{Programs to meet cultural needs of Indigenous patients}

Overall, a third or less of the CR services provided specific programs or activities to meet the cultural needs of Indigenous patients (Table 5). Case management for Indigenous patients was offered by $32 \%$ of CR services: this was higher for rural programs (50\%) compared with remote (17\%) and metropolitan (33\%). Specific educational materials for Indigenous patients were provided by $35 \%$ of CR services: this was greater for metropolitan programs (58 \%) compared with rural and remote programs (20\% and $25 \%$ respectively). A buddy or mentoring system for Indigenous patients was offered by $27 \%$ of programs with a similar proportion by rurality. Overall $71 \%$ of programs reported being able to access an Aboriginal Health Worker with rural and remote programs ( $80 \%$ and $83 \%$ respectively) having greater access than metropolitan programs (50\%).

Metropolitan services reported that they referred Indigenous patients to the Indigenous specific program provided by the AMS for CR and secondary prevention. In the regional area with an AMS chronic condition program, it was reported that most Indigenous patients accessed the AMS program. Remote services were more likely to identify Indigenous people (Table 5) and provide additional activities to meet the cultural needs of Indigenous patients (83 \%) compared with rural (30 \%) and metropolitan (25\%) services, particularly in those regions in northern WA with a higher proportion of Indigenous people (100\%). Culturally appropriate activities included separate classes for men and women, home visits, visits to Aboriginal Communities, an Indigenous Therapy/Allied Health Assistant leading the classes, and a specific Indigenous group with a breakfast club and exercise class.

\section{Cultural awareness professional development}

Overall, $97 \%$ of coordinators $(\mathrm{n}=33)$ reported receiving cultural awareness training within their organisation, $100 \%$ of rural and remote and $91 \%(\mathrm{n}=11)$ of metropolitan programs (Table 5). One metropolitan program did not receive cultural awareness training and a response was not recorded from another. A range of cultural awareness training options were utilised. In rural and remote regions training was most commonly provided through the mandatory Western Australian Country Health Services (WACHS) online training which in some instances was supplemented by video conference training, or face-to-face training from a local Aboriginal Corporation or local Language and Cultural Centre. Non-WACHS programs utilised a Heart Foundation presentation on Aboriginal CR or a university cultural awareness program. Cultural awareness delivery in the metropolitan setting included hospital-based e-learning supplemented by optional Indigenous cultural study days. Community programs included training from the Heart Foundation, Aboriginal Health Council of WA, Aboriginal Medical Service and the Health Department when staff also worked clinically in a hospital setting.

\section{Cardiac rehabilitation guideline use}

Overall, $77 \%$ of coordinators reported that their program was based on CR guidelines: $60 \%$ rural, $67 \%$ remote, and $100 \%$ of metropolitan programs (Table 5). The National Heart Foundation of Australia and Australian Cardiac Rehabilitation Association Recommended Framework for Cardiac Rehabilitation'04 [14] was the most frequently utilised (60 \%) CR guideline. The ACRA Core Components of Cardiovascular Disease Secondary Prevention and Cardiac Rehabilitation 2014 [43] and the 2014 Department of Health, Western Australia, Cardiovascular rehabilitation and secondary prevention pathway principles for Western Australia [44] were utilised by $15 \%$ of the CR services. No coordinators reported utilising the National Health and Medical Research Council, Strengthening Cardiac Rehabilitation and Secondary Prevention for Aboriginal and Torres Strait Islander Peoples: A Guide for Health Professionals [41]. Twenty percent of programs utilised more than 
one set of guidelines, including WA Models of Care and interstate or international programs/ guidelines such as the Flinders Chronic Condition Management Program [45, 46], Statewide Cardiology Clinical Network's Cardiac Rehabilitation: a Model of Care for South Australia [47] or American Heart Association's Cardiac Rehabilitation and Secondary prevention of Coronary Heart Disease Scientific Statement [18]. A minority (9\%) of CR Coordinators were unsure of the guidelines utilised and $6 \%$ stated that their program was "not really" guideline based.

\section{Discussion}

Multifaceted strategies to promote access to flexible CR and secondary prevention services tailored to meet the needs, preferences and cultural safety of individuals are required [10]. Patient-centred access to health care is complex and as conceptualised by Levesque et al., includes 5 dimensions: Approachability; Acceptability; Availability; Affordability; and Appropriateness [48]. According to Levesque there are 5 corresponding abilities needed to interact with the dimensions of accessibility: Ability to perceive; Ability to seek; Ability to reach; Ability to pay; and Ability to engage [48]. The Strengthening Cardiac Rehabilitation and Secondary Prevention for Aboriginal and Torres Strait Islander Peoples: A Guide for Health Professionals was developed to provide strategies for improved access to and uptake of CR for Indigenous Australians. [41]. In this study, despite evidence of much good practice, we demonstrate a continuing access gap to CR and secondary prevention services for Indigenous Australians in WA.

\section{Access to CR services in Western Australia}

Lack of referral to and enrolment in CR has been significantly related to a drive time of over $60 \mathrm{~min}$ so geographical location is a major determinant of access to CR for many people living rurally [29]. Clark et al. reported that approximately $95 \%$ of Australians live within $1 \mathrm{~h}$ of basic services to support CR and secondary prevention, including $75 \%$ of the Indigenous population [49]. Conversely, they report that $14 \%$ of Indigenous people live in geographical regions with poor access to health services that provide CR [49]. In WA, $63.2 \%$ of the Indigenous population live outside of Metropolitan Perth with higher proportions living in the Kimberley (43 \%), Pilbara (16\%), Midwest (12\%), and Goldfields (12\%). However, only $31.6 \%$ of CR services were located in larger regional cities or towns of the Kimberley, Pilbara, Midwest and Goldfields, an area of some $2,312,237 \mathrm{~km}^{2}$ or $87.4 \%$ of the total WA land mass. Thus a major access barrier for many Indigenous patients in WA is the lack of available CR service provision and the challenge of reaching services. Alternative methods of CR delivery such as home-based CR via telehealth or mobile health platforms may overcome this geographical isolation [11].

The Strengthening Cardiac Rehabilitation and Secondary Prevention for Aboriginal and Torres Strait Islander Peoples: A Guide for Health Professionals recommend that $\mathrm{CR}$ for Indigenous patients draw on existing CR and secondary prevention services as appropriate (Table 1, key Measure 3) [41]. We identified a limited number of services that provided CR and secondary prevention specific to Indigenous patients. Given that $C R$ programs were not generally provided in AMS's in WA, it is essential that CR services ensure cultural safety is integral to their core business and they take the specific needs of Indigenous Australians into consideration in planning and delivering $\mathrm{CR}$, including alternative methods of CR delivery (Table 1, Key measures 1 and 6).

\section{Identification, participation and completion rates for Indigenous patients}

To effectively improve access to $\mathrm{CR}$ and meet the cultural needs of Indigenous people, they must firstly be identified as Indigenous. Thompson et al., reported that fewer than half (47.7 \%) of CR services had processes in place for identifying Indigenous status [40]. Our findings demonstrate improvement in this, especially in remote WA, but there are opportunities to improve this in one third of services not currently identifying Indigenous status.

Shepherd and colleagues reported low Indigenous participation in structured general practice-based CR in remote Queensland [38]. Lack of knowledge about CR, possibly relating to a lack of referral was demonstrated as a barrier to CR participation [38]. To overcome such disparities requires coordination to enable continuity of care for Indigenous patients. Integrated pathways are likely to occur when there are effective partnerships and information flow between health services and referral networks [41, 42]. Metropolitan public hospitals were identified by all $\mathrm{CR}$ coordinators as a referral pathway but referrals from other health care providers such as private hospitals or general practice was reported by less than two thirds of coordinators and made a minor contribution to referrals. This indicates a need for more effective information flow from all systems of care provision that a patient encounters following an acute cardiac event. Integrated clinical referral pathways, education and awareness raising of all health providers and electronic record alerts in general practice provide potential solutions to increase across system checks and referrals.

Coordinator responses indicate a wide variation in the number of Indigenous patients attending $\mathrm{CR}$ in WA, largely related to geographical location and population 
density. Respondents reported low numbers of referrals but a higher proportion of Indigenous attendance in northern WA, corresponding to a larger Indigenous population in these regions. A lower level of attendance at metropolitan services was attributed to referral of Indigenous patients to the AMS program although there is no data on the proportion of Indigenous patients who require $\mathrm{CR}$ who actually attend this program. The Perth metropolitan area covers $6,418 \mathrm{~km}^{2}$ so issues of distance still exist for Indigenous people who are more likely to live in the outer metropolitan suburbs, although the AMS's provision of a transport service for patients is an important component of access.

Respondents had difficulty reporting attendance and completion rates for Indigenous and nonIndigenous patients for many reasons: the openended nature of some programs; the lack of a clear definition of completion; and inconsistencies in collection of data. A standardised and consistent method of data collection in Australia would enable accurate evaluation and could prompt advocacy for service improvement for Indigenous patients [22, 43]. The ACRA Core Components of Cardiovascular Disease Secondary Prevention and Cardiac Rehabilitation 2014 [43] and the Cardiovascular Rehabilitation and Secondary Prevention Pathway Principles for Western Australian [44] recommend the collection of a minimum dataset to record and monitor CR practice in Australia and WA. The ACRA Core Components [43] offer a comprehensive list of data that may be collected, but for rural and remote services with limited capacity a minimum data set would be preferable.

\section{Programs to meet cultural needs of Indigenous patients}

According to Levesque, for services to be accessible they must be acceptable and appropriate, thus allowing people to seek and engage [48]. For CR to be acceptable and appropriate it needs to take the personal, social and cultural needs of the patient into account and provide culturally appropriate care, resources and tools to empower self-management and autonomy (Table 1, Key measures 2, 4 and 6) $[41,48,50]$. Measures that met the cultural needs of Indigenous patients include the availability of an Aboriginal Health Professional [22, 41], availability of specific educational materials for Indigenous Australians [41], case-management by cardiac coordinators [42], and having a buddying or mentoring system in place [37], however, these are not routinely available [44]. In WA, the majority of CR services were able to access an Aboriginal Health Worker and/or Liaison Officer but a limited number of services were able to offer specific educational materials, case-management or a buddying system. Provision of alternative methods of home-based CR for Indigenous patients that incorporate a family and a community buddy $[37,42]$ with professional support from a cardiac coordinator and Indigenous Health Professional may help overcome the cultural barriers characteristic of traditional-CR services.

\section{Cultural awareness professional development}

Cultural safety, integral to the core business of an organisation (Table 1, Key measure 1), requires specialist resource development and training for continuing professional development for all health professionals working in heart health care, including Aboriginal Health Workers, Liaison Officers and Allied Health Assistants (Table 1, Key measure 7) [41]. It is a health professional's responsibility to ensure they receive cultural awareness training and practice in a culturally safe manner and the responsibility of the organisation to provide support and training to ensure that services are provided in a culturally respectful way [41]. The extent to which this form of training translates into the provision of culturally safe care is not clear, and it is important to realise that it is the whole system of care which will influence a patient's experience of a service.

\section{Cardiac rehabilitation guideline use}

Evidence-based guidelines are important in promoting best-practice and driving practice change [40]. This also applies to the promotion of cultural awareness and culturally safe practice. Organisations providing a CR service need to develop or utilise supportive protocols, policies and procedures that address the personal, social and cultural needs of patients (Table 1, Key measure 6) [41]. The Strengthening Cardiac Rehabilitation and Secondary Prevention for Aboriginal and Torres Strait Islander Peoples: A Guide for Health Professionals in 2008 $[40,41]$ was an excellent resource that includes strategies and tools for the provision of culturally appropriate $\mathrm{CR}$ programs to improve the uptake and access to $\mathrm{CR}$ for Indigenous people. However, Thompson et al. reported suboptimal awareness and limited implementation in WA in 2008 and disturbingly no CR service was utilizing this guide in 2015.

The ACRA Core Components of Cardiovascular Disease Secondary Prevention and Cardiac Rehabilitation 2014 [43] and the Cardiovascular rehabilitation and secondary prevention pathway principles for Western Australia [44] acknowledge the barriers to Indigenous patients accessing $\mathrm{CR}$ and the need for patient-centred culturally appropriate CR services. Details of culturally appropriate patient resources were provided but they did not discuss specific strategies or resources for providing culturally appropriate care nor did they reference the Strengthening Cardiac Rehabilitation and Secondary Prevention for Aboriginal and Torres Strait Islander 
Peoples: A Guide for Health Professionals [41] which if utilised would help guide health professionals working in $\mathrm{CR}$ services to provide better care for Indigenous patients.

\section{Strengths, limitations and implications}

The strength of our study relates to the in-depth assessment undertaken, the rich level of data obtained from the CR coordinators and high participation of services in the study. Limitations arise from CR services in WA and Australia lacking a standard method of data collection which limits the availability of quantitative client data and our ability to make direct comparisons between services and report inferential statistics. All three guidelines previously discussed recommend the collection of information to identify problem areas and measure change [41], a minimum dataset to record and monitor CR and secondary prevention in WA [44] that could be used to evaluate the quality and outcome of an individual's participation for each of the five core components of CR [43]. A further limitation is the inability to estimate the number of Indigenous patients who are not referred to $\mathrm{CR}$, as access to concurrent discharge data for the number of eligible patients was not included in the study design. The relatively high level of completion of $C R$ described by coordinators indicates that an essential step in CR delivery is referral and initial attendance. Finally, there is an absence of Aboriginal people's views of $C R$ service provision in this study, a gap that has been previously identified $[37,51,52]$ but there are relatively few reports in the literature.

Our results have important implications for $\mathrm{CR}$ and secondary prevention delivery for Indigenous patients in Western Australia. Ongoing quality improvement of CR services and the provision of culturally appropriate, flexible, accessible and guideline-based alternative methods of CR delivery need to be explored. Continued efforts to ensure Indigenous status is identified, endorsement of guideline implementation, and a structured integrated health pathway to ensure coordinated management of $\mathrm{CR}$ and secondary prevention are essential. Awareness raising and continuing professional development for all health professionals involved in supporting the patient's journey is necessary to improve knowledge of and use of CR guidelines. Our findings suggest that a minimum data set enabling assessment of service key performance indicators for all phases of $\mathrm{CR}$ could underpin quality improvement and improve tracking of patient referral, attendance, adherence and completion rates. If implemented at a national level, there are opportunities to establish relevant benchmarks and accountability for service function in urban, rural and remote settings.

Advances in technology provide avenues to add value to centre-based CR services. Mobile health technology has been successfully trialled for the delivery of a comprehensive CR program in Brisbane, with improved uptake and completion rates and improved health outcomes equal to centre-based CR [53]. Application of this technology has great potential for improving access in rural and remote Australia but is still to be tested in these settings and its utility to support Indigenous people remains to be assessed.

\section{Future directions}

To address the findings from this in-depth assessment of $\mathrm{CR}$ services in WA, the authors and partners are progressing the implementation and evaluation of an innovative and validated mobile health platform for the delivery of home-based comprehensive CR in WA. A context-sensitive implementation study will utilise a collaborative participatory approach with the Indigenous community and health service providers to ensure the program is culturally appropriate for Indigenous and non-Indigenous Western Australians.

\section{Conclusions}

The under-representation of Indigenous Australians participating in $\mathrm{CR}$, as reported in the literature and more specifically in this study, mandates a concerted effort to improve services to better meet the needs of Indigenous patients with CVD as part of closing the gap in life expectancy. Improving access to culturally appropriate $\mathrm{CR}$ and secondary prevention in Western Australia must be an important component of this effort given the high rates of premature cardiovascular disease affecting Indigenous people. Our findings highlight the importance of good systematic data collection across services, establishing benchmarks that enable regular monitoring and upskilling of all health staff involved in supporting CVD patients to ensure they are aware of CR guidelines and promote uptake. Health pathways that ensure continuity of care and alternative methods of CR delivery with dedicated resources are needed.

\section{Abbreviations \\ ACRA, Australian Cardiovascular Health and Rehabilitation; AHW, Aboriginal Health Worker; AMS, Aboriginal Medical Service; CHD, Coronary Heart Disease; CPD, Continuing Professional Development; CR, Cardiac rehabilitation; CVD, Cardiovascular disease; HACC, Home and Community Care Program; NHMRC, National Health and Medical Research Council; WA, Western Australia; WACHS, Western Australian Country Health Service}

\section{Acknowledgements}

We gratefully acknowledge the health services and all the Cardiac Rehabilitation Coordinators who participated. The National Heart Foundation WA develops and maintains the Directory of Western Australian Cardiac Rehabilitation and Secondary Prevention Services.

Funding

Dr Hamilton is a Poche Research Fellow and acknowledges support from the UWA Poche Centre of Indigenous Health. The WA Centre for Rural Health receives core support from the Australian Department of Health. 


\section{Availability of data and materials}

Data supporting the findings reported are contained within this manuscript.

\section{Authors' contributions}

SH contributed to the study conception and design, secured ethical and governance approvals, stakeholder engagement, data collection, analysis, interpretation and writing. BM contributed to study design, ethical approval, stakeholder engagement, data collection and writing. SM contributed to stakeholder engagement and writing. SCT contributed to study conception and design, interpretation and writing. All authors approved the final manuscript.

\section{Competing interests}

The authors declare that they have no competing interests.

\section{Consent for publication}

Not applicable

\section{Ethics approval and consent to participate}

The Western Australian Country Health Service and University of Western Australia Human Ethics Committees approved the study. Coordinators returned a signed consent form and were re-consented verbally at the beginning of the interview for their responses to be digitally recorded.

\section{Author details}

${ }^{1}$ Western Australian Centre for Rural Health, University of Western Australia, 35 Stirling Highway, Crawley, WA 6009, Australia. ${ }^{2}$ National Heart Foundation of Australia, 334 Rokeby Road, Subiaco, WA 6009, Australia.

\section{Received: 19 January 2016 Accepted: 21 June 2016}

\section{Published online: 13 July 2016}

\section{References}

1. Australian Bureau of Statistics. Causes of Death, Australia, 2013 (3303.0). Canberra: 2013. http://www.abs.gov.au/ausstats/abs@.nsf/Lookup/ by\%20Subject/3303.0 2013 Main\%20Features Leading\%20Causes\% 20of\%20Death 10001.

2. Australian Institute of Health and Welfare 2014. Health-care expenditure on cardiovascular diseases 2008-09. Cat. no. CVD 65. Canberra: AlHW; 2014.

3. Australian Institute of Health and Welfare. Cardiovascular disease, diabetes and chronic kidney disease - Australian facts: Mortality. Cardiovascular, diabetes and chronic kidney disease series no. 1. Cat. no.CDK 1. Canberra: AlHW; 2014.

4. Australian Institute of Health and Welfare. Coronary heart disease and chronic obstructive pulmonary disease in Indigenous Australians 2014, Cat. no. IHW 126. Canberra: AlHW.

5. Australian Institute of Health and Welfare. Cardiovascular disease, diabetes and chronic kidney disease - Australian facts: Aboriginal and Torres Strait Islander people. Cardiovascular, diabetes and chronic disease no.5. Cat. no. CDK 5. Canberra: AlHW; 2015.

6. Zhao YGS, Mangus A, Vos T. Burden of disease and injury in Aboriginal and non-Aboriginal populations in the Northern Territory. Med J Aust. 2004; 180(10):498-502.

7. Katzenellenbogen JM, Sanfilippo FM, Hobbs MS, Briffa TG, Ridout SC, Knuiman MW, Dimer L, Taylor KP, Thompson PL, Thompson SC. Incidence of and case fatality following acute myocardial infarction in Aboriginal and non-Aboriginal Western Australians (2000-2004): a linked data study. Heart Lung Circ. 2010;19(12):717-25.

8. Katzenellenbogen JM, Teng THK, Lopez D, Hung J, Knuiman MW, Sanfilippo FM, Hobbs MST, Thompson SC. Initial hospitalisation for atrial fibrillation in Aboriginal and non-Aboriginal populations in Western Australia. Heart. 2015; 101(9):712-9.

9. Teng T-HK, Katzenellenbogen JM, Thompson SC, Sanfilippo FM, Knuiman M, Geelhoed E, Hobbs M, Bessarab D, Hung J. Incidence of first heart failure hospitalisation and mortality in Aboriginal and non-Aboriginal patients in Western Australia, 2000-2009. Int J Cardiol. 2014;173(1):110-7.

10. Briffa T, Kinsman L, Maiorana A, Zecchin R, Redfern J, Davidson P, Paull G, Nagle A, Denniss A. An integrated and coordinated approach to preventing recurrent coronary heart disease events in Australia. Policy statement from the Australian Cardiovascular Health and Rehabilitation Association. Med J Aust. 2009;190(12):683-6.
11. Clark RA, Conway A, Poulsen V, Keech W, Tirimacco R, Tideman P. Alternative models of cardiac rehabilitation: a systematic review. Eur J Prev Cardiol. 2015;22(1):35-74.

12. Anderson L, Oldridge N, Thompson DR, Zwisler A-D, Rees K, Martin N, et al. Exercise-Based Cardiac Rehabilitation for Coronary Heart Disease: Cochrane Systematic Review and Meta-Analysis. J Am Coll Cardiol. 2016;67(1):1-12.

13. Briffa TG, Hobbs MS, Tonkin A, Sanfilippo FM, Hickling S, Ridout SC, Knuiman M. Population Trends of Recurrent Coronary Heart Disease Event Rates Remain High. Circ Cardiovasc Qual Outcomes. 2011;4(1):107-13.

14. National Heart Foundation of Australia \& Australian Cardiac Rehabilitation Association: Recommended Framework for Cardiac Rehabilitation 04. National Heart Foundation of Australia, Melbourne, 2004. www.heartfoundation.com.au. Accessed 27 Nov 2015.

15. Evenson KR, Fleury J. Barriers to outpatient cardiac rehabilitation participation and adherence. J Cardiopulm Rehabil. 2000;20(4):241-6.

16. Bunker S, McBurney H, Cox H, Jelinek M. Identifying Participation Rates at Outpatient Cardiac Rehabilitation Programs in Victoria, Australia. J Cardiopulm Rehabil. 1999;19(6):334-8.

17. Scott I, Lindsay K, Harden H. Utilisation of outpatient cardiac rehabilitation in Queensland. Med J Aust. 2003;179(7):332-3.

18. Leon A, Franklin B, Costa F, Balady G, Berra K, Stewart K, Thompson P, Williams M, Lauer M. Cardiac rehabilitation and secondary prevention of coronary heart disease. Circulation. 2005;111(3):369-76.

19. Shanmugasegaram S, Oh P, Reid R, McCumber T, Grace S. Cardiac rehabilitation barriers by rurality and socioeconomic status: a cross-sectional study. Int J Equity Health. 2013;12(1):72.

20. Worcester MU, Stojcevski Z, Murphy B, Goble AJ. Factors associated with non-attendance at a secondary prevention clinic for cardiac patients. Eur J Cardiovasc Nurs. 2003;2(2):151-7.

21. Wenger NK. Current Status of Cardiac Rehabilitation. J Am Coll Cardiol. 2008:51(17):1619-31.

22. Briffa TG, Kinsman L, Maiorana AJ, Zecchin R, Redfern J, Davidson PM, Paull G, Nagle A, Denniss AR. An integrated and coordinated approach to preventing recurrent coronary heart disease events in Australia. Med I Aust. 2009;190(12):683-6.

23. Clark AM, King-Shier KM, Duncan A, Spaling M, Stone JA, Jaglal S, Angus J. Factors influencing referral to cardiac rehabilitation and secondary prevention programs: a systematic review. Eur J Prev Cardiol. 2013;20(4):692-700.

24. Clark AM, King-Shier KM, Thompson DR, Spaling MA, Duncan AS, Stone JA, Jaglal SB, Angus JE. A qualitative systematic review of influences on attendance at cardiac rehabilitation programs after referral. Am Heart J. 2012;164(6):835-45. e2

25. Grace SL, Gravely-Witte S, Brual J, Monette G, Suskin N, Higginson L, Alter DA, Stewart DE. Contribution of patient and physician factors to cardiac rehabilitation enrollment: a prospective multilevel study. Eur J Cardiovasc Prev Rehabil. 2008;15(5):548-56.

26. Caldwell PH, Arthur HM. The influence of a "culture of referral" on access to care in rural settings after myocardial infarction. Health Place. 2009;15(1):180-5.

27. Redfern J, Maiorana A, Neubeck L, Clark AM, Briffa T. Achieving coordinated secondary prevention of coronary heart disease for all in need (SPAN). Int J Cardiol. 2011:146(1):1-3.

28. Redfern J, Ellis E, Briffa T, Freedman S. High risk-factor level and low risk-factor knowledge in patients not accessing cardiac rehabilitation after acute coronary syndrome. Med J Aust. 2007;186(1):21-5.

29. Brual J, Gravely-Witte S, Suskin N, Stewart D, Macpherson A, Grace S. Drive time to cardiac rehabilitation: at what point does it affect utilization? Int J Health Geogr. 2010;9:27.

30. Harlan 3rd WR, Sandler SA, Lee KL, Lam LC, Mark DB. Importance of baseline functional and socioeconomic factors for participation in cardiac rehabilitation. Am J Cardiol. 1995;76(1):36-9.

31. Beswick A, Rees K, West R, Taylor F, Burke M, Griebsch I. Improving uptake and adherence in cardiac rehabilitation: literature review. J Adv Nurs. 2005; 49(5):538-55.

32. Brown TM, Hernandez AF, Bittner V, Cannon CP, Ellrodt G, Liang L, Peterson ED, Piña IL, Safford MM, Fonarow GC:. Predictors of Cardiac Rehabilitation Referral in Coronary Artery Disease Patients: Findings From the American Heart Association's Get With The Guidelines Program. J Am Coll Cardiol. 2009;54(6):515-21.

33. Cortes $\mathrm{O}$, Arthur HM. Determinants of referral to cardiac rehabilitation programs in patients with coronary artery disease: a systematic review. Am Heart J. 2006;151(2):249-56. 
34. Johnson NP, Fisher JB, Nagle AP, Inder KBNG, Wiggers JP. Factors Associated With Referral to Outpatient Cardiac Rehabilitation Services. J Cardiopul Rehab. 2004;24(3):165-70.

35. Barber K, Stommel M, Kroll J, Holmes-Rovner M, McIntosh B. Cardiac rehabilitation for community-based patients with myocardial infarction: Factors predicting discharge recommendation and participation. J Clin Epidemiol. 2001;54(10):1025-30.

36. Jackson L, Leclerc J, Erskine Y, Linden W. Getting the most out of cardiac rehabilitation: a review of referral and adherence predictors. Heart. 2005; 91(1):10-4.

37. Taylor KP, Smith JS, Dimer L, Ali M, Wilson N, Thomas TR, Thompson SC. "You're always hearing about the stats ... death happens so often": new perspectives on barriers to Aboriginal participation in cardiac rehabilitation. Med J Aust. 2010;192(10):602.

38. Shepherd F, Battye K, Chalmers E. Improving access to cardiac rehabilitation for remote Indigenous clients. Aust N Z J Public Health. 2003;27(6):632-6.

39. Australian Bureau of Statistics 2011 Census Data: Community Profiles. http://www.abs.gov.au/websitedbs/censushome.nsf/home/communityprofiles.

40. Thompson S, DiGiacomo M, Smith J, Taylor K, Dimer L, Ali M, Wood M, Leahy T, Davidson P. Are the processes recommended by the NHMRC for improving Cardiac Rehabilitation (CR) for Aboriginal and Torres Strait Islander people being implemented?: an assessment of CR Services across Western Australia. Aust NZ Health Policy. 2009;6(1):29.

41. National Health and Medical Research Council. Strengthening Cardiac Rehabilitation and Secondary Prevention for Aboriginal and Torres Strait Islander Peoples: A Guide for Health Professionals. Australia: NHMRC; 2005.

42. Ilton MW, Walsh WF, Brown AD, Tideman PA, Zeiltz CJ, Wilson J. A framework for overcoming disparities in management of acute coronary syndromes in the Australian Aboriginal and Torres Strait Islander population. Med J Aust. 2014;200(11):639-43.

43. Woodruffe S, Neubeck L, Clark RA, Gray K, Ferry C, Finan J, Sanderson S, Briffa TG. Australian Cardiovascular Health and Rehabilitation Association (ACRA) Core Components of Cardiovascular Disease Secondary Prevention and Cardiac Rehabilitation 2014. Heart Lung Circ. 2015;24(5):430-41.

44. Department of Health WA: Cardiovascular rehabilitation and secondary prevention pathway principles for Western Australia. Perth: Health Strategy and Networks, Department of Health; 2014. http://www.healthnetworks. health.wa.gov.au/network/cardio_rehab.cfm. Accessed 27 Nov 2015.

45. Battersby MA, Ask A, Markwick MM, Collins J, Reece MM. The Partners in Health scale: the development and psychometric properties of a generic assessment scale for chronic condition self-management. Aust J Prim Health. 2003:9(2-3):41-52.

46. Battersby MW. Health reform through coordinated care: SA HealthPlus. Brit Med J. 2005:330(7492):662-5.

47. Statewide Cardiology Clinical Network: Cardiac Rehabilitation: a Model of Care for South Australia - an overview. Government of South Australia 2011.

48. Levesque JF, Harris MF, Russell G. Patient-centred access to health care: conceptualising access at the interface of health systems and populations. Int J Equity Health. 2013:12:18.

49. Clark RA, Coffee N, Turner D, Eckert KA, van Gaans D, Wilkinson D, Stewart S, Tonkin AM. Access to cardiac rehabilitation does not equate to attendance. Eur J Cardiovas Nur. 2014;13(3):235-42.

50. Department of Health WA. WA Chronic Conditions Self-Management Strategic Framework. Perth: Helath Networks Branch, Department of Health, Western Australia; 2011.

51. DiGiacomo ML, Thompson SC, Smith JS, Taylor KP, Dimer LA, Ali MA, Wood MM, Leahy TG, Davidson PM. 'I don't know why they don't come': barriers to participation in cardiac rehabilitation. Aust Health Rev. 2010;34(4):452-7.

52. Davey M, Moore W, Walters J. Tasmanian Aborigines step up to health: evaluation of a cardiopulmonary rehabilitation and secondary prevention program. BMC Health Serv Res. 2014;14(1):349.

53. Varnfield M, Karunanithi M, Lee CK, Honeyman E, Arnold D, Ding H, Smith C, Walters DL. Smartphone-based home care model improved use of cardiac rehabilitation in postmyocardial infarction patients: results from a randomised controlled trial. Heart. 2014:100(22):1770-9.

\section{Submit your next manuscript to BioMed Central and we will help you at every step:}

- We accept pre-submission inquiries

- Our selector tool helps you to find the most relevant journal

- We provide round the clock customer support

- Convenient online submission

- Thorough peer review

- Inclusion in PubMed and all major indexing services

- Maximum visibility for your research

Submit your manuscript at www.biomedcentral.com/submit 